Journal of Science and Technology, Vol. 29, No. 3 (2009), pp 72-85

(C) 2009 Kwame Nkrumah University of Science and Technology (KNUST)

\title{
DIMENSIONS OF BASIC SCHOOL DROPOUTS IN RURAL GHANA: THE CASE OF ASUTIFI DISTRICT
}

\author{
B. Imoro \\ Department of Planning \\ Kwame Nkrumah University of Science and Technology \\ Kumasi - Ghana
}

\begin{abstract}
The objective of this paper was to investigate the various dimensions of basic school dropouts in rural Ghana using the Asutifi district as a case study. The analysis of data (both quantitative and qualitative) gathered from several stakeholders of basic education in the district, revealed that the causes of school dropout were rather complex. Poor educational outcomes in terms of performance of candidates in the final examinations of the basic level as a result of the poor quality of teaching and learning in the rural environment was directly linked to the high rate of dropout. Although some stakeholders claimed that poverty was the main cause of school dropout, the significance of the loss of confidence in the educational system cannot be overemphasised. The policy implication is that quality consideration in the basic education delivery should now be the priority in order to regain the confidence of parents and their wards in the educational system in general so that enrolments and retention of children in school could be enhanced.
\end{abstract}

Keywords: Basic Education, Dropout, Quality, Enrolment, Retention

\section{INTRODUCTION}

Many countries of the so-called developing world invest heavily in the development of education because it is regarded as the sin qua non for social, political and economic development (Fobih, 1987; Hanf et al., 1975). In many African countries the opportunity cost of investment in the educational sector is exacerbated by persistent school dropout especially at the basic level. Under such circumstances researchers are under constant pressure from frustrated policy makers to determine the causes of this menace. The Government of Ghana's concern about persistent basic school dropout has been well stated in the Ghana Poverty Reduction Strategy (Government of Ghana, 2003) and measures were outlined in the Ministry of Education Strategic Plans to address the phenomenon. To complement government efforts, several Non Governmental Organisations (NGO) in conjunction with various development partners, are implementing intervention packages in high risk areas in Ghana to solve the problem.

Several research works including those of Awedoba et al., (2003) and Braimah and OduroOfori (2005) indicate that parents in Ghana are aware of the value of formerly educating their wards. The annual ritual of anxiety demon- 
strated by parents and their wards in the quest for admissions into Senior High Schools (SHS), Universities and Polytechnics may be regarded as a manifestation of the level of awareness of the value of education in Ghana.

In spite of this awareness and the efforts of Government, NGOs and development partners, dropout rates remained high at about $20 \%$ for boys and $30 \%$ for girls at primary school and $15 \%$ for boys and $30 \%$ for girls at Junior High School (JHS) level (Government of Ghana, 2003). The rates are even much higher for rural districts like Asutifi and worse in the three northern regions. In view of these circumstances and the burning desire of the various stakeholders in the sector to retain children in school, the need for a study to determine the evolving complex mix of causes of school dropout to guide the myriad of policies and programmes being designed and implemented cannot be overemphasised.

\section{The Concept of School Dropout}

According to Awedoba et al., (2003:45) dropout typically refers to a pupil's permanent withdrawal from School. Brimer and Pauli (1971) defined a school dropout as a person who leaves school before the end of the final year of the education stage in which he or she is enrolled. It can be deduced from the latter definition that leaving school after the completion of basic school without proceeding to the next levels does not technically constitute dropout. Dropout at the basic level is an undesirable situation because those who drop out are not likely to have strengthened their basic literacy skills so they easily relapse into illiteracy (Brimer and Pauli, 1971).

Although school dropout is a worldwide phenomenon there are variations in terms of dimensions and causes due to social, psychological and economic differences in the world. These not withstanding, some lessons could be learned from best practices in controlling the menace around the world. According to Foraker (1999) dropout rates among German schools was relatively low because of institu- tional differentiation according to children's abilities and interests. It is also interesting to note that in the German education system, dropouts have been associated with the low social prestige schools like the "hauptschulen" mainly due to problems of discipline and occasional vandalism. In fact Fetler (1989) found out that schools with higher achievements had rather lower dropout rates.

Colbey (2000) observed that parents seek favourable outcomes such as good academic achievement and eventual employment but try to avoid negative outcomes such as children's disrespect for their parents, delinquency of school leavers, school girls' objection to traditional rules governing marriage and their inability to master the required domestic duties etc. Parents' seeking to avoid such traits might withhold their children from school or withdraw those already in school.

Causes of high dropouts in Ghana have been attributed to a range of factors including lack of books and supplies, poor teaching, lack of teachers, long walking distances to school, high cost of school materials, pregnancy, early marriage, etc. As stated in the Ghana Poverty Reduction Strategy document nearly one-third of children who dropped out of school cited the need to work as the reason whilst another onethird cited cost as the reason (Government of Ghana, 2003). The two reasons are closely linked up because children from poor homes are the ones most likely to be in need of work to earn income or provide supplementary family labour. Thus child labour and the phenomenon of street children popularly called "kayaye" are social problems that are often attributable to poverty and are inextricably linked to school dropouts either as causes or effects.

Whilst many parents are quick to attribute the dropout phenomenon to poverty, those who have ample knowledge of the livelihood patterns and attitudes of parents to education like teachers, opinion leaders and educational authorities often express doubts about this assertion. Most of them claim that parents, especially in high incidence areas, have priorities 
other than the education of their children. This implies that there are several complex dimensions of the basic school dropout phenomenon in the different locations in Ghana.

In the 2003 GPRS implementation monitoring report, it was noted that the beneficial impact of expanding access to education could be achieved only if education was of good quality and parents/guardians perceived good returns to investment in their children's education in terms of good outcomes (NDPC, 2003). If parents believe that their children are not receiving quality and relevant education, they will not send and retain their children in school. Furthermore, if parents loose confidence in the quality of education that their children are receiving they will rationally encourage their wards to dropout of school. With these observations, the rate of dropout could be an indirect indicator of the quality of education and the confidence in the education system (NDPC, 2003; Smith, 2003)

\section{Research Questions}

In view of the complexity of the factors that accounts for school dropout, the following research questions were designed to unearth the various dimensions of the phenomenon.

- Are the dropout rates significantly high in the district?

- What are the views of stakeholders regarding the causes of the dropout phenomenon?

- To what extent can the decisions to dropout of school be rational?

- What are the policy implications for the rationality of school dropout?

Study Scope and Methods of Data Collection The Asutifi District was created in 1988 and it is considered to be one of the deprived districts in the Brong Ahafo Region of Ghana (Asutifi District Assembly, 2002). It is predominantly rural with only $15.3 \%$ of the entire population of 84,485 in year 2000 living in two urban settlements (with population above 5,000), i.e. Kenyase No. 2 and Hwidiem. The remaining $84.7 \%$ of the population live in 115 rural settlements with population less than 5,000.
This paper examines the complex dimensions of the phenomenon of dropouts in the Asutifi District. The data for the analysis is based on a study commissioned by ActionAid Ghana in 2004 to determine the causes and effects of basic school dropout in the District.

The study covered school dropouts at the Basic School, i.e. from Primary school class one to JHS form three. The study sought to determine the trend of basic school dropout rates in the district using enrolment data from 1997/98 to 2003/2004 academic years. Data on school enrolment were collected from the District Education office.

The various stakeholders whose views were sought to investigate the intricate dimensions of the dropout phenomenon included the District Director of Education, the Guidance and Counselling officers, head teachers, chiefs, Assembly members, school children, the dropouts themselves and their parents. The views were assembled through individual as well as group interviews using questionnaires. Two schools in two settlements from each of the six circuits were randomly sampled from which teachers, school children and dropouts and their parents were then sampled and interviewed. The schools covered included Acherensua Catholic basic schools and Konkontreso L/A in the Acherensua circuit, Mehame Catholic, Dadiesoaba Methodist and Catholic basic schools in the Dadiesoaba circuit, Kenyase No. 3 and Koforidua L/A schools in the Goamu circuit, Hwidiem Methodist and Ola basic schools in the Hwidiem circuit, Kenyase No. 2 Catholic and TI Ahmadiyya basic schools in the Kenyase circuit and finally Gambia No.1 and Nsuta L/A schools in the Kenyase-Muoho circuit. An analysis of the dropout patterns and main causes are presented as follows.

\section{ANALYSIS OF ENROLMENT AND DROPOUTS IN THE ASUTIFI DISTRICT}

In terms of educational facilities the district is endowed with 12 private schools and 162 public schools. Whilst $24 \%$ of the schools were at the Pre-school level, 2\% were at SHS level. For the purpose of this study, only JHS and Primary 
schools (i.e. $74 \%$ of the schools) were considered excluding the SHS and Pre-schools.

\section{Dropouts at the Primary Level}

Enrolment figures were used to determine dropouts due to the non-availability of data distinguishing children who had actually dropped out of school from those that had transferred to other schools. This was due to the fact that majority of the parents do not go to the schools to collect their wards' cumulative records books when they are transferring their children to other schools. As a result of this the reduction in enrolments that have been considered as dropouts could include transfers to other schools. Although this was a limitation to the study, the effect was minimal since transfers within the district would reflect in other schools as increased enrolments.

Analysis of the data indicated that primary school enrolment dropped from 12,289 in $1997 / 98$ academic year to 12,124 the following year but picked up in 1999/2000 and increased gradually to 12,705 in the year $2003 / 2004$. Thus over the period from $1997 / 98$ to $2003 / 04$ primary school enrolment increased by only $3 \%$. This was not encouraging considering the fact that the Free Compulsory Universal Basic Education (fCUBE) programme was envisaging a massive increase in school enrolment. On the whole, for almost all classes or years, the enrolment of boys exceeded that of girls.
The dropout figures for the primary schools were derived from enrolment in each class as they progressed. These dropout figures were then used to determine the annual dropout rates for all primary schools in the district. The 1998/99 academic year registered the highest number of dropouts (i.e. 1,223) within the period under consideration. However unlike the enrolment where there was a gradual increase over the years, the dropout phenomenon did not appear to follow any particular trend with rather significant fluctuations. As indicated in figure 1, the dropout for girls far exceeded that for boys. Whilst many more boys enrolled every year, many more girls dropped out of primary school every year. The district therefore had a daunting challenge of retaining girls in school.

\section{Dropouts at the JHS Level}

The dropouts at the JHS level were also determined using enrolment data. The dropout rates at this level were significantly higher than those at the primary schools (see Table 1). This is rather quite alarming because after managing to go through primary school many children tend to dropout of school at the JHS level.

\section{Trend Analysis of Dropouts}

Apart from determining dropouts on an annual basis as stated above, the level of dropouts can best be appreciated by tracing a cohort from start to end of a school cycle. Using the enrol-

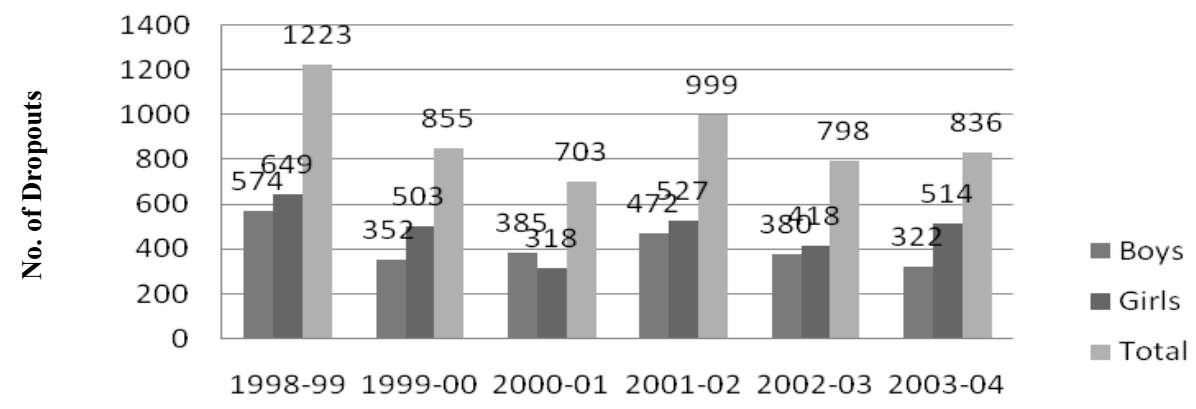

Academic Year

Fig. 1: Primary School Dropouts 1998/99 - 2003/04 

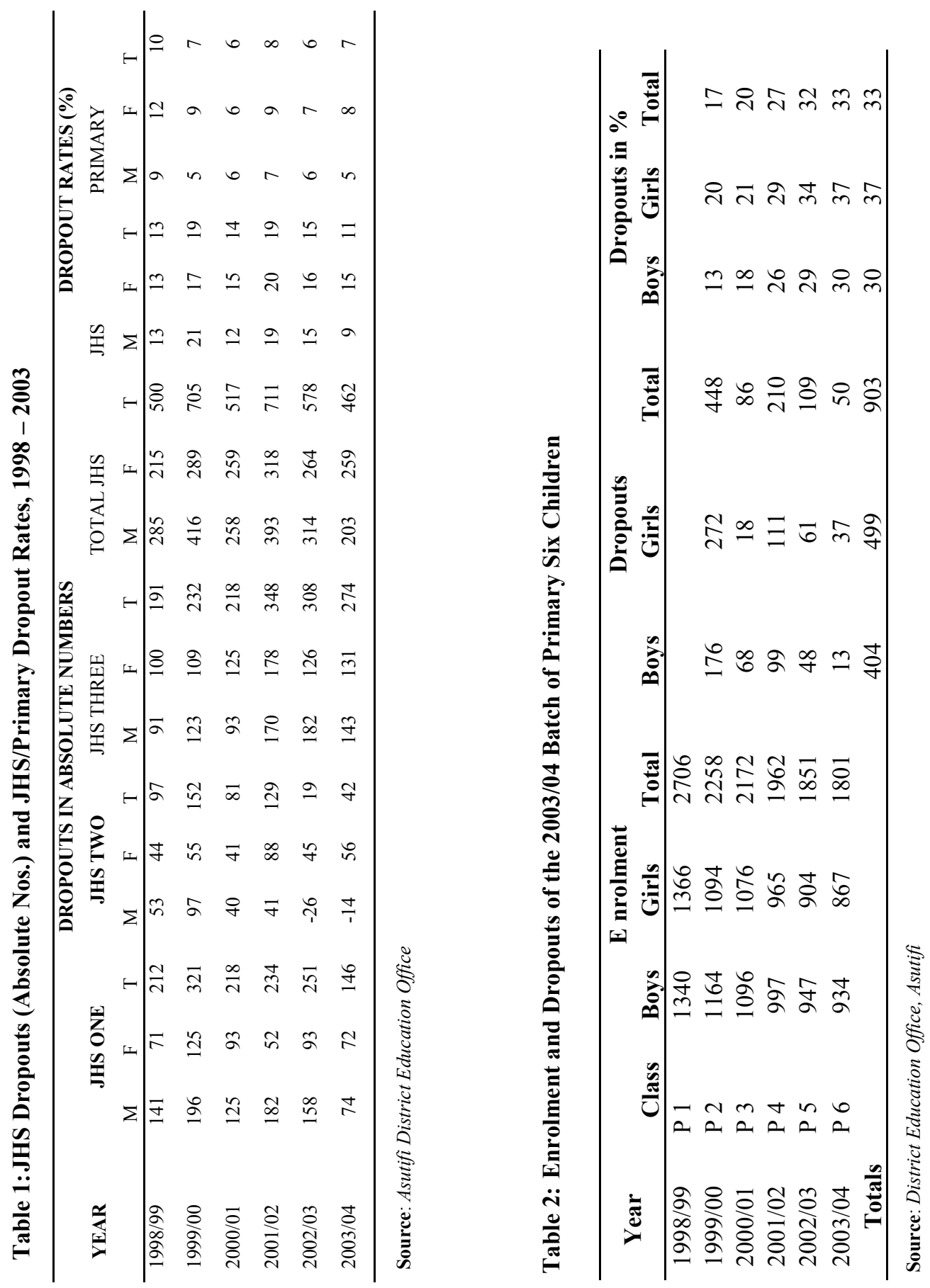
ment data in the Asutifi District, the rate at which the 2003/2004 batch of children in primary six depreciated over the years from primary one to six is presented in Table 2. This batch started primary one in 1998 with a total of 2,706 pupils comprising of 1,340 boys and 1,366 girls. The sex ratio reversed the following year (i.e. in class 2) with as many as 272 girls leaving school. After six years in primary school $37 \%$ of the girls who started school in 1998 stopped school whilst $30 \%$ of the boys left school. In all, 33\% of the children stopped schooling by the time they reached class six.

The same analysis was done for the 2003/2004 batch of JHS 3 children by tracing their enrolment as far back as 1997 when they were in Primary 3. As shown in Table 3 the dropout rate rose sharply as they moved to the JHS and continued at a very high rate. From primary three to JHS 3 as many as $41 \%$ of the boys and $48 \%$ of the girls dropped from school. Generally, the dropout rates were higher at the JHS than the primary level and also the rate for girls was more than that for boys. The primary school dropout rates of $30 \%$ and $37 \%$ for boys and girls were much higher than the national average of $20 \%$ and $30 \%$ respectively. At the JHS level the rates of $41 \%$ and $48 \%$ were also higher than the national average of $15 \%$ and $30 \%$ for boys and girls respectively.
MAIN CAUSES OF SCHOOL DROPOUTS

In view of the fact that the causes of dropouts are complex and interrelated they have been presented here along broad thematic areas.

\section{Poverty Related Causes}

According to the Asutifi District Assembly (2002) the district economy is predominantly agrarian and like many deprived districts in Ghana majority of the people are peasant farmers who still depend on rudimentary methods of production resulting in low output. Consequently household income is very low and poverty is widespread.

With this background about the district economy it was not surprising that many stakeholders saw poverty as the main cause of dropouts. All dropouts who were contacted claimed that poverty was the main reason why they abandoned school. However many of the teachers and counselling officers did not agree with the rest that poverty was the main reason. They claimed that the dropout phenomenon was more prevalent among the settlers because their priority was not the education of their children. According to the teachers, some of these families spend lavishly on funerals, expensive clothing and other social events whilst neglecting the education of their children.

Table 3: Enrolment Trend and Dropouts for the 2003/2004 Batch of JHS 3 from 1997

\begin{tabular}{lcrrrrrrrrr}
\hline \multirow{2}{*}{ Year } & \multirow{2}{*}{ Class } & \multicolumn{3}{c}{ Enrolment } & \multicolumn{3}{c}{ No. of Dropouts } & \multicolumn{3}{c}{ Dropouts Rates (\%) } \\
\cline { 2 - 10 } & & Boys & Girls & Total & Boys & Girls & Total & Boys & Girls & Total \\
\hline $1997 / 98$ & P 3 & 1097 & 909 & 2006 & & & & & & \\
$1998 / 99$ & P 4 & 1041 & 812 & 1853 & 56 & 97 & 153 & 5 & 11 & 8 \\
$1999 / 00$ & P 5 & 966 & 763 & 1729 & 75 & 49 & 124 & 12 & 16 & 14 \\
2000/01 & P 6 & 946 & 701 & 1647 & 20 & 62 & 82 & 14 & 23 & 18 \\
Sub-Total (From P 3-6) & & & & 151 & 208 & 359 & & & \\
$2001 / 02$ & JHS 1 & 764 & 649 & 1413 & 182 & 52 & 234 & 30 & 29 & 30 \\
$2002 / 03$ & JHS 2 & 790 & 604 & 1394 & -26 & 45 & 19 & 28 & 34 & 31 \\
$2003 / 04$ & JHS 3 & 647 & 473 & 1120 & 143 & 131 & 274 & 41 & 48 & 44 \\
Sub-Total (From JHS 1 - JHS 3) & & & 450 & 436 & 274 & 41 & 48 & 44 \\
\hline
\end{tabular}

Source: District Education Office, Asutifi 


\section{Poor Examination Results}

The settler communities were also contacted to verify the allegations and it was revealed that the people had lost confidence in the educational system producing desirable outcomes that could enable their wards to progress beyond the basic level. They acknowledged the value of educating their children but they did not see the sense in leaving their children in school knowing very well that they could not proceed to the higher levels due to poor performance in the Basic Education Certificate Examinations (BECE). It was stated at Mehame that many parents did not see any prospects in their children progressing to the higher levels of education because of the poor performance of children in the BECE.

The deduction here is that although poverty was generally cited as one of the main causes, another equally important cause was the poor quality of education which manifests itself in the poor academic performance of children and their subsequent inability to progress to the higher levels of the educational ladder. Some parents added that if the quality were guaranteed they could sacrifice other things for the education of their children because they knew it was a useful investment for the future of their wards and themselves as well.

Poor Image of Schools due to Poor Academic Performance

The school children themselves including those who dropped out of school maintained that apart from the poverty related causes, the poor image of schools in the district due to the poor performance of candidates in the BECE was a major cause of school dropout.

Using examination results as a measure of quality it can be deduced from the available statistics that the image of the schools in the district from 1997 to 2000 was not the best. Among the 13 districts in the region, Asutifi placed $11^{\text {th }}$ in terms of level of performance of the BECE candidates in 1997. In 1998 and 1999 the district remained in position number 12 within the region. The situation became worse in 2000 when the district took the last position in terms of the performance of its BECE candidates in the examination with only $33.6 \%$ of the 1,038 candidates presented passing the examinations to qualify for admission into SHS.

According to all the stakeholders contacted, the high dropout rate of the JHS candidates in the district could be associated with the poor performance of the candidates in the BECE over the years. The downward trend in the performance of the candidates from 1997 to 2000 , prompted the authorities to review the policy of mass promotion. As indicated in Table 4 below, the performance of the candidates moved the district from the $13^{\text {th }}$ in 2000 to the $4^{\text {th }}$ position in 2001 and in 2002 the district moved to an envious position of being first in the region. At the national level, the candidates' performance in the BECE placed the district in the $12^{\text {th }}$ position in the BECE league table among the then

Table 4: BECE Results of Asutifi District (1997 - 2003)

\begin{tabular}{lcccc}
\hline Year & Candidates & No. Passed (6-30) & \% Passed & Position in Region \\
\hline 1997 & 1124 & 694 & 62 & $11^{\text {th }}$ \\
1998 & 1146 & 259 & 22.6 & $12^{\text {th }}$ \\
1999 & 1180 & 349 & 29.6 & $12^{\text {th }}$ \\
2000 & 1038 & 349 & 33.6 & $13^{\text {th }}$ \\
2001 & 1125 & 621 & 55.2 & $4^{\text {th }}$ \\
2002 & 954 & 774 & 81.1 & $1^{\text {st }}$ \\
2003 & 1066 & 764 & 72.1 & $2^{\text {nd }}$ \\
\hline
\end{tabular}

Source: Regional and District Education Office Records 
110 districts in the country with $81 \%$ of the candidates presented passing the BECE to qualify for admission to SHS.

This rather impressive performance of the district was attributed to the decision by most schools to repeat academically weak students instead of promoting them en mass. Many of the schools decided to temper with the mass promotion policy by conducting promotion examinations for candidates in JHS 2 and allowing only those who passed to move to JHS 3 and to subsequently register for the BECE. This implies that only candidates who could pass the examination were presented, hence the good performance. The lesson here is the critical role of quality control measures.

As indicated in Table 4, the number of candidates presented dropped from 1,125 in 2001 to 951 in 2002 but increased slightly to 1,066 in 2003. The consequence of this measure was that many of the pupils who could not pass the examination decided to leave school entirely, and this led to a high dropout rate in the district from JHS 1 to JHS 2 of about 20\% in only one year and among one year group. For instance in 2002/2003 the enrolment at JHS 2 stood at 1,394 and by the following year the enrolment reduced to 1,120 in JHS 3 with as many as 274 $(20 \%)$ of them abandoning school. There was also a massive dropout from class six to JHS1 and the same reason was assigned for the high dropout. Many of the children did not return to their schools for fear of being teased by their colleagues because they failed. At the Ahmadiyya JHS at Kenyase No. 2, 34 JHS 2 pupils sat for the promotion examination to enter JHS 3 but only 10 were allowed to register for the 2004 BECE. Majority of the $70 \%$ who could not pass the examination refused to repeat and either left for other schools or took up apprenticeship to learn a trade.

Although the measure had an immediate effect of increasing the number of dropouts, the District Education Office believed that the dropout rate would ultimately reduce due to the fact that the image and reputation of the schools in the district was rising because of the good perform- ance. The general view was that if parents gain some confidence in the schools in the district, they will maintain their children in the schools instead of allowing them to dropout. This measure was thus likely to reduce the level of dropouts at all levels, thus confirming the assertion by Fetler (1989) that schools with higher achievements have lower dropout rates.

According to the teachers, the measure had instilled some level of discipline and seriousness in the students. The fact that the number of candidates passing the promotion examination increased immediately after a drastic fall of 1,066 from 2001 to 2003 suggest that with time, more and more may pass the examinations and the level of dropout could reduce further.

\section{Unattractive School Environment}

The attractiveness of both the physical and social environments of the school can whip up and sustain children's interest in school. The need for good and safe school buildings and surrounding compounds cannot be overemphasised if children's interest in school is to be maintained. Although the efforts of NGOs, the District Assembly and other interventions like the Social Investment Fund (SIF) in the construction and maintenance of school buildings are remarkable, some school buildings remain in very deplorable conditions. It could not have been by accident that the school with the best physical and social environment among the sampled schools did not have any dropouts and their enrolments were comparatively higher than most schools? Any visitor to Dadiesoaba will not fail to notice the JHS building with a neat compound dotted with trees some of which had seats for children to sit and read comfortably during break times. The beautiful physical environment appeared to be well complimented by a good social environment because no pupil was found loitering about.

Children's interest in school can be maintained if teachers are friendly and school children are disciplined. The views of many stakeholders regarding the best environment for effective 
teaching and learning concerned both teachers and children's attitudes. Three of the group interviews with school children placed truancy and the scare of being beaten by teachers as one of the main causes of school dropout. However all the group interviews with school children were unanimous in the view that children's interest in school could be raised and maintained if sports could be promoted.

Unattractiveness of the teaching and learning environment may be attributable to many factors and it is only when these factors are dealt with adequately that enrolment and retention of children in school can be enhanced. Definitely making the environment attractive depends on the ability of intervention measures to address the needs and requirements of both teachers and school children. Failure to address these issues promotes absenteeism on the part of both teachers and pupils with the obvious consequences being low academic performance.

\section{Teenage Pregnancy}

One reason for the higher dropout rate of girls was teenage pregnancy. According to records from the Brong Ahafo Regional Education Office, four of the six girls from the Asutifi District failed to write the BECE in 2001 after they had been registered because they were pregnant. According to one of the Guidance and Counselling Officers in the district, some of the girls become sexually active by the end of their primary school education and without proper education about their sexuality they easily fall prey to men including their own school mates and teachers. In one of the sampled schools it was reported that a girl was raped by a teacher in 2003 and she got pregnant and abandoned school. Teenage pregnancy was mentioned as one major cause of girls dropping out of school. The unfortunate situation was that those girls who get pregnant were unable to return to school because their own school mates tease them. Even in situations where the school rules were made flexible enough to allow pregnant girls to write examinations, they faced a barrage of derogatory remarks from their peers and even older women. Those who attempted to return to school after delivery also faced the problem of stigmatisation. According to the Girl-Child Counselling Officer, only one girl in Hwiediem was able to brave it to continue school after delivery.

There are other reasons why the rate at which girls dropped out of school was much higher than boys. According to one Counselling Officer, when girls encounter problems they tend to keep their problems to themselves and this often affects their academic performance. Others also get too engrossed with love affairs to the detriment of academic work. Others also get preoccupied with domestic chores at home so they do not find sufficient time to learn. The ultimate result of all these problems was that the girls performed poorly in examinations. During one of the group interviews with primary school boys they had the impression that girls were generally stupid. If this reflects somehow the general impression of the wider society then the probability of parents not showing any particular attention to girl-child education could be very high.

The poor performance of girls in school in addition to the non-existence of female role models within the local communities are factors that influence or fuel higher female dropouts from school. According to some stakeholders, many families tend to withdraw their girls from school to go and stay with their more affluent relations in the cities to serve as housemaids. All these culminate in higher dropout rates for girls in the district.

\section{Peer Influence}

Peer influence drives most of the boys in particular into truancy and other anti-social behaviour like gambling, stealing and the use of narcotic drugs including smoking of "Indian hemp". Such children normally leave home and instead of going to school they secretly join their friends, who may be school dropouts themselves but are now what is commonly referred to as "station boys". These boys are normally found around lorry stations helping drivers and passengers to load and offload vehicles 
in the more urbanised communities in the district such as Kenyase No. 2 and Hwidiem. At Kenyase where one of such dropouts due to peer influence was identified and contacted he claimed to have stopped schooling due to poverty.

Some of the school children reported that pupils who associate themselves with the station boys tend to cause trouble in school and are often under constant surveillance by school authorities. For such children the school environment does not appeal to them so they often look for the slightest opportunity to slip off and join their friends at the lorry stations. Some of such deviants use their school fees to gamble or buy drugs and so they are often driven home to bring their fees. Such children rarely perform well in examinations and ultimately drop out of school.

\section{Shortage of Teachers}

Shortage of teachers is a common feature in many schools in the district. For the 2003/2004 academic year, the District Education Office declared 109 vacant teaching positions. The fact that over $60 \%$ of the sampled teachers had not taught for more than three years in their current schools was an indication that there was a high mobility of teachers in the district. Even among the head teachers contacted only one had stayed in his current duty post for eight years. Many of the teachers were newly trained teachers who were compulsorily posted to the schools to teach. Most of them were only waiting for the mandatory three years to qualify for study leave so that they use the excuse of going back to school to leave the district. Some of the teachers agreed that their last years were often characterised by high rates of absenteeism because they travel frequently to follow up arrangements for their further studies. The implication here is that in addition to lack of teachers, the children suffer from lost of actual teaching hours and this adversely affects the academic performance of the pupils, which ultimately drives them out of school.

The district has been using volunteer teachers and untrained teachers popularly called "pupil teachers" to fill the gap. During the 2002/2003 academic year the public primary schools had as many as $35 \%$ whilst the JHS had $15 \%$ untrained teachers. The private schools (both Primary and JHS), who were always at the top in terms of the performance of their candidates in the BECE had 94\% untrained teachers. The SHS graduates who could not secure places in the limited tertiary institutions could be recruited to teach in the rural areas just like the volunteers supported by ActionAid. These teachers could be sponsored to go to the training colleges and bonded for a number of years if they are able to rewrite their examinations to get the requisite grades to enter training colleges.

In fact, the school children even at the primary school indicated that one of the reasons why school was not attractive to some children was the problem of insufficient teachers. They further added that, if there are no teachers and no sports facilities to engage them, school becomes so boring that children will exploit the least opportunity to stay away.

\section{Broken Homes and Single Parenthood}

Although school dropout as a result of broken homes did not feature significantly in the district there were a few reported cases in Koforidua and Kenyase. Broken homes in such a predominantly rural community compels the resulting single parent (especially the females) to migrate to the urban areas leaving behind the children in the care of either grandparents or the extended family. When remittances for the upkeep of the children left behind are not forthcoming the probability of such children dropping out of school is very high.

Only two cases of single parenthood as a result of death of partners were encountered in the survey. When such isolated incidences occur in a poor family the children left behind tend to drop out of school. These are the victims that desperately need the support of benevolent organisations such as ActionAid, ISODEC, Otumfuo Educational Fund etc. 


\section{Migration}

As earlier stated, majority of the population in the district are settler farmers. Most of these migrants who still maintain links with their places of origin or hometowns have a tendency to move their children very frequently and this could affect their academic performance which could consequently lead to more dropouts.

High levels of poverty and unemployment compel people in the district to migrate from the rural areas to the urban and metropolitan centres within the country to find jobs. According to the two mothers of the four dropouts contacted at Koforidua, their children were temporally out of school because their fathers had migrated to Accra to seek for better jobs and had not returned. Such children are likely to drop out completely from school if their fathers are not able to find jobs in time. Others also dare to join the popular emigration to the Western World to seek greener pastures through every route possible including risky ones through the Sahara desert. When such attempts fail, and more often than not they fail, the end result is more misery which tends to manifest itself in high dropout.

\section{Implications of the Main Causes of Dropout} Although JHS and SHS graduates who are unable to gain admission into the SHS and tertiary institutions respectively are technically not dropouts, the general public see them as such. Consequently the inability of these graduates from predominantly rural districts like Asutifi to obtain competitive grades to qualify for admission into the highly prestigious SHS and tertiary institutions in the country has far reaching implications for enrolment and retention of children in school. It is a fact that basic schools in rural areas cannot compete with those in urban areas because the latter are able to mobilise resources to establish quality teaching and learning environments that will attract both teachers and pupils.

Children in the more urbanised schools are able to pass well and take up most of the places in the well endowed SHS, whilst their counterparts in the rural based JHS end up going to the less endowed SHS where the probability of obtaining the requisite passes for the more competitive tertiary level institutions is very limited. Subsequently many of the children from rural schools either end up as "dropouts" from the JHS or SHS. This is a great disincentive for parents to send their children to school and to keep them in school. If parents perceive the probability of performing well in school is limited, they will rationally prefer withdrawing their children from school to engage them in economic activities or early apprenticeship. The implication of this rather more complex and entrenched causes of school dropouts need to be addressed from all angles with special emphasis on quality improvement of rural schools.

\section{Recommendations}

The complexity of the problem of school dropout in rural Ghana requires a comprehensive approach involving both policy and investment initiatives. The need for policies to retain children in school and to facilitate their transition from JHS through SHS to the tertiary level cannot be overemphasised.

There are several ways by which the informal apprenticeship system could be integrated into the formal educational system to strengthen the vocational components of the technical (JHS) schools. Since the vocational aspect of the JHS system has been over shadowed by the quest for everyone to proceed to the SHS and straight to the University, partnership with the private sector for the practical training of students at the technical schools will be a better option.

The Government's initiative of developing a model SHS in each district to ease the competition for the few relatively endowed SHS is commendable and should be vigorously pursued by the GETFund. It should be expanded to cover the technical schools as well in order to de-emphasise the theoretical straight jacket training from JHS through SHS to the University. Opportunities should then be sought for the technical school graduates to proceed to the polytechnics. According to the Ministry of Education Strategic Plan (MESP, 2003) gov- 
ernment was to come out with a Technical and Vocational Education and Training (TVET) policy in collaboration with the other Ministries, Departments and Agencies (MDAs) and the private sector. This was in recognition of the fact that TVET was not properly integrated into the JHS system and so WAEC examinations tend to de-emphasise "hands-on training". This will ensure that those who have no opportunities for advancement through the SHS find alternatives.

One other policy review that is worth consideration is the integration of untrained teachers or pupil teachers into the mainstream professional teaching career. It is unfortunate that these untrained teachers, who need refresher courses and workshops, are often rather left out because they are not professional teachers no matter how long they teach. Since some research findings and empirical evidence have proved that untrained teachers could be used to produce good results, it is high time the Ministry reconsidered this policy to absorb this category of teachers to fill the yawning gap of teachers in the rural areas in particular. The fact that $90 \%$ of the teachers of the private schools in the Asutifi district were untrained and yet they produced the best results proves the point. Another policy review that is long overdue is the policy of mass promotion within the basic school system. The attempt by some schools in the district to introduce some promotion examination for the JHS yielded some positive results by way of some vast improvement in the performance of their candidates in the BECE. Many of the teachers interviewed indicated that the promotion examination tends to instil discipline and some level of seriousness in the children. Although the short term effect was an increase in dropouts, the school authorities believe that once it is institutionalised across all schools, the effect on dropout will be minimal. The measure however has an invaluable long term benefit because the image of the schools in the district could be enhanced to restore the lost confidence that parents and children had for rural schools like those in the Asutifi District.
In addition to the policy reviews suggested above the following measures could be undertaken to enhance enrolment and retention of children in school.

\section{Formation of Counselling Groups in Basic Schools}

The formation of Guidance and Counselling groups comprising of teachers, parents, pupils/ students and opinion leaders to track and help children with problems could go a long way to identify would-be dropouts before they actually fall out. Regular interaction of the groups with pupils and students could unearth their problems for quick resolution to enable them stay in school. Also, the group should explain and demonstrate the dangers associated with truancy and peer group pressure/influence to the children. Peer counselling could eliminate the tendency of pupils to mock at their colleagues for either failing examinations, returning to school after delivery or getting pregnant. The Counsellors could also assist in identifying genuinely needy children for support by the existing benevolent organisations such as ActionAid, Otumfuo Education Fund etc. These organisations could support the formation and maintenance of these groups to ensure sustainability.

Parent Teacher Association (PTA) and School Management Committees (SMCs)

The PTAs and SMCs in the various communities need to be encouraged to foster constant interaction between parents and teachers in the various schools and communities. Teachers should endeavour to get in touch with the parents of children who have problems to discuss issues affecting their wards.

\section{Promoting the Spirit of Competition among Schools}

The District's education directorate could raise the level of interest of school children in school by encouraging inter-school competitions in sporting as well as academic activities. This will require the support of all stakeholders which can only be forthcoming if the school 
PTAs and SMCs are properly organised and tasked with the responsibility of mobilising resources to support such competitions.

\section{Creation of Incentives for Child Retention in School}

The implementation of the fCUBE is flawed with conceptual misinterpretations that must be carefully reviewed to emphasise the development and use of incentives to attract children and retain them in school. This is in line with some established views that laws that make schooling compulsory were less likely to succeed and that initiatives that make schooling attractive by improving access to quality facilities have better chances of addressing issues like school dropouts and child labour.

Thus signatories to the Ghana NGO Coalition on the Rights of the Child (GNCRC), which was established in 1995, need to double their efforts to address issues like dropouts and child labour with the relevant ministries such as Ministry of Education, Ministry of Youth and Sports, Ministry of Women and Children Affairs, Social Welfare and the National Commission on Children.

\section{CONCLUSION}

The study established the persistent and complex nature of the phenomenon of school dropout in the Asutifi district. The solution of such a problem therefore requires comprehensive and far reaching measures that will range from policy reviews, establishment of strong institutions and investment in the provision of educational infrastructure. Comprehensive approaches that will ensure that quality teaching and learning environments are established across all schools will provide clear motivation to parents to send their children to school and retain them in school. The study also revealed that the need to address the issue of transition from basic level to the tertiary level of education in order to restore some level of confidence of parents in the educational system in the rural areas.

If the hope of achieving positive outcomes in school is complemented by attractive school environments, parents will be encouraged to send their children to school and to keep them in school whilst children will resist pressures to drop out of school. This is a sustainable way to address the problem of school dropout especially in rural districts like Asutifi in Ghana..

\section{REFERENCES}

Asutifi District Assembly (2002). Asutifi Medium Term Development Plan (2002 2005), Kenyase

Awedoba, A.K., Yoder, P.S., Fair, K. and Gorin, S. (2003). Household demand for schooling in Ghana, ORC Macro, Calverton, Maryland USA

Braimah, I. and Oduro-Ofori, E. (2005). Basic school dropout in Ghana: A case study of the Amansie West District, Journal of Science and Technology, 25 (1), 67-76.

Brimer, M. A. and Pauli, L. (1971). Wastage in Education; a World Problem, UNESCO, IBE, Paris.

Colbey, J. (2000). Defining quality in education, UNICEF working paper series, Paper presented at the International working group meeting on education, Florence, Italy, June 2000

Fetler, M. (1989). School dropout rates, academic performance, size and poverty: Correlates of educational reform, in Educational Evaluation and Policy Analysis, 11 (2), 109-116

Foraker, W.C. (1999). "The perception of ability differences in German education." In Contemporary Research in the United State, Germany, and Japan on Five Education Issues: Germany, Archived Information accessed on 10/12/2006 from http:// www.ed.gov/pubs/Research5/Germany/ standards g.html

Fobih, D.K. (1987). Social-psychological factors associated with school dropout in the Eastern Region of Ghana, The Journal of Negro Education, 56(2), 229-239 
Government of Ghana (2003). Ghana Poverty Reduction Strategy 2002-2006, NDPC, Accra

Hanf, T., Ammann K., Dias, P.V., Fremerey M. and Weiland, H. (1975). Education: An obstacle to development? Some remarks about political functions of education in Asia and Africa, Comparative Education Review, February 1975, 68 - 86

MESP (2003). Ministry of Education Strategic Plan 2003 - 2015, Ministry of Education, Accra
NDPC (2003). Implementation of the Ghana Poverty Reduction Strategy, 2003 annualmonitoring report, NDPC, Accra .

Smith, R. L. (2003). "School disaffection: Africa's growing problem", The International Journal on School Dissatisfaction, Trenthen Books, accessed from www.dropout prevention.org on 12/12/2007 